\title{
Are Fast Food "Trans-Fat" Claims True? An Infraspec VFA-IR Spectrometer Analysis of Trans-fat content in select food items purchased from Long John Silver's
}

\author{
Sharron Jenkins*, Patty Campbell and Charmita Burch
}

Purdue University North Central, 1401 S US HWY 421 Westville Ga and Georgia Gwinnett College, 1000 University Lane, Lawernceville Ga, USA

\section{H R O N I C L E}

Article history:

Received May 6, 2014

Received in revised form

July 02, 2014

Accepted 8 August 2014

Available online

19 August 2014

Keywords:

Fat

Trans-Fat

Fast-Food

ATR-FTIR

Spectroscopy

\begin{abstract}
A B S T R A C T
Studies linking high trans-fat diets to coronary heart disease (CHD) have prompted the need to regulate, limit, or completely ban trans-fat from all commercial food products, including fast foods. Many U.S. fast food chains now claim that their food items, particularly French fries, have "no trans-fat". In a previous study, our lab tested the validity of trans-fat claims made by several popular fast food restaurants by experimentally determining the \%trans-fat in oil extracted from fast food French fries. In some cases, the trans-fat content was nearly twice as high as the amount reported by the restaurant in their literature. Long John Silver's, for example, reported a trans-fat content of $25 \%$ for their French fries, while our lab actually found over $40 \%$ trans-fat. The purpose of this study is to broaden our study of Long John Silver's trans-fat claims by analyzing a variety of their food items and comparing our findings with the \%trans-fat reported by the restaurant literature (nutrition fact tables). Variable Filter Array (VFA) IR spectroscopy was used to assess the trans-fat content of oil extracted from food samples. Our preliminary findings suggest that nearly every food item under study contained considerably more trans-fat than the amount reported in the restaurant's literature.
\end{abstract}

C 2014 Growing Science Ltd. All rights reserved.

\section{Introduction}

A trans-fat (Fig. 1) is a fat molecule containing one or more unsaturated fatty acids in the trans configuration. Trans-fats are produced industrially by a process called hydrogenation ${ }^{1}$. Studies linking high trans-fat diets to coronary heart disease (CHD) have prompted the need to regulate, limit, or completely ban trans-fat from all commercial food products, including fast foods ${ }^{2-4}$. An intake of just 5 grams of trans-fat a day has been linked to a 25 percent increase in the risk of ischemic heart disease and Americans intake an average of 5.8 grams of trans-fat a day ${ }^{5,7}$.

In order to help reduce the risk of disease, the American Heart Association recommends limiting the amount of dietary trans-fat consumption to less than 2 grams a day ${ }^{8}$. In addition, in 2003 the U.S. Food and Drug Administration, amended its nutrition labelling regulations to require that "trans fatty

* Corresponding author.

E-mail address: sjenkin2@ggc.edu (S. Jenkins) 
acids be declared in the nutrition label of conventional foods and dietary supplements" to help consumers make healthy dietary choices ${ }^{5}$. To date, there are no federal regulations or monitoring of trans-fat labelling of fast foods purchased from fast food establishments ${ }^{5,8}$. Consumers rely solely on restaurant establishments to report accurate and up-to-date nutritional data. As of July 2008, New York City banned the use of trans-fat in all food service establishments ${ }^{9}$. Since this ban, many fast food restaurants have voluntarily switched to "no trans-fat" frying ${ }^{1,10,11}$.

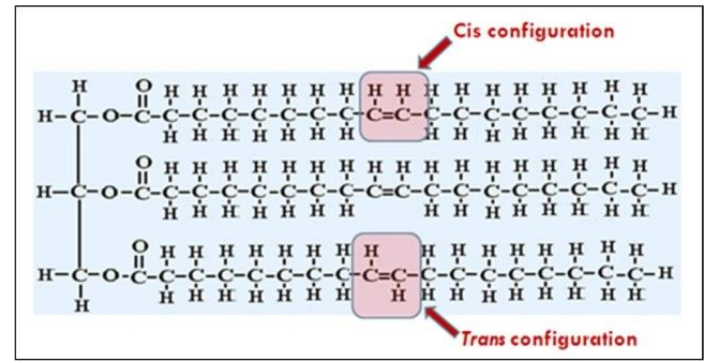

Fig. 1. Fat Molecule (cis/trans)

In a previous study, our lab tested the validity of trans-fat claims made by several popular fast food restaurants by experimentally determining the \%trans-fat in oil extracted from fast food French fries $^{12}$. In some cases, trans-fat content was nearly twice as high as the amount reported by the restaurant in their literature. Long John Silver's (LJS), for example, reported a trans-fat content of $25 \%$ for their French fries, while our lab actually found over $40 \%$ trans-fat. The purpose of this study is to broaden our study of LJS's trans-fat claims by analyzing a variety of their food items and comparing our findings with the \%trans-fat reported in restaurant literature (nutrition fact tables).

Rapid VFA-IR spectroscopy is used to determine the total isolated trans-fatty acids in oil samples extracted from LJS's food items ${ }^{11}$. This type of IR analysis is based on a C-H "out-of-plane" deformation that is characteristic of all compounds containing an isolated trans double bond configuration. The trans configuration results in a unique IR absorbance band at $966 \mathrm{~cm}^{-1}$ and the intensity of this absorption band can be used to determine trans-fat content in a variety of fat samples ${ }^{11}$.

\section{Results and Discussion}

Table 1 and Fig. 2 compare the experimental values (as the mean of three trials and standard deviation from mean) and literature values (LJS's nutrition fact table) of the \%trans-fat and \%fat in oil extracted from twelve different food items purchased from LJS's. For all food items studied, the \%trans-fat was considerably higher than the values reported in LJS's 2010 literature. The fat extracted from "Breaded Fish" was nearly 50\% trans-fat, which is 4 grams of trans-fat in just one serving. Ten out of the 12 food items studied contained over $40 \%$ trans-fat.

Direct comparison of our experimental data with restaurant literature values could be misleading since we were not able to evaluate the statistical significance of the literature values or how the restaurant trans-fat analyses were done. Hence, we cannot state the statistical or quantitative significance of our data in comparison with literature values. The new novel instrument used in our analysis is a proven, valid method of trans-fat analysis. Therefore, it is clear that our data should raise concern about the significant amounts of trans-fat in fast foods and the accuracy of trans-fat reporting by restaurants ${ }^{12,17}$. Our data has serious health implications for consumers; especially since the American Heart Association recommends limiting the amount of dietary trans-fat intake to less than 2 grams a day ${ }^{12}$. 


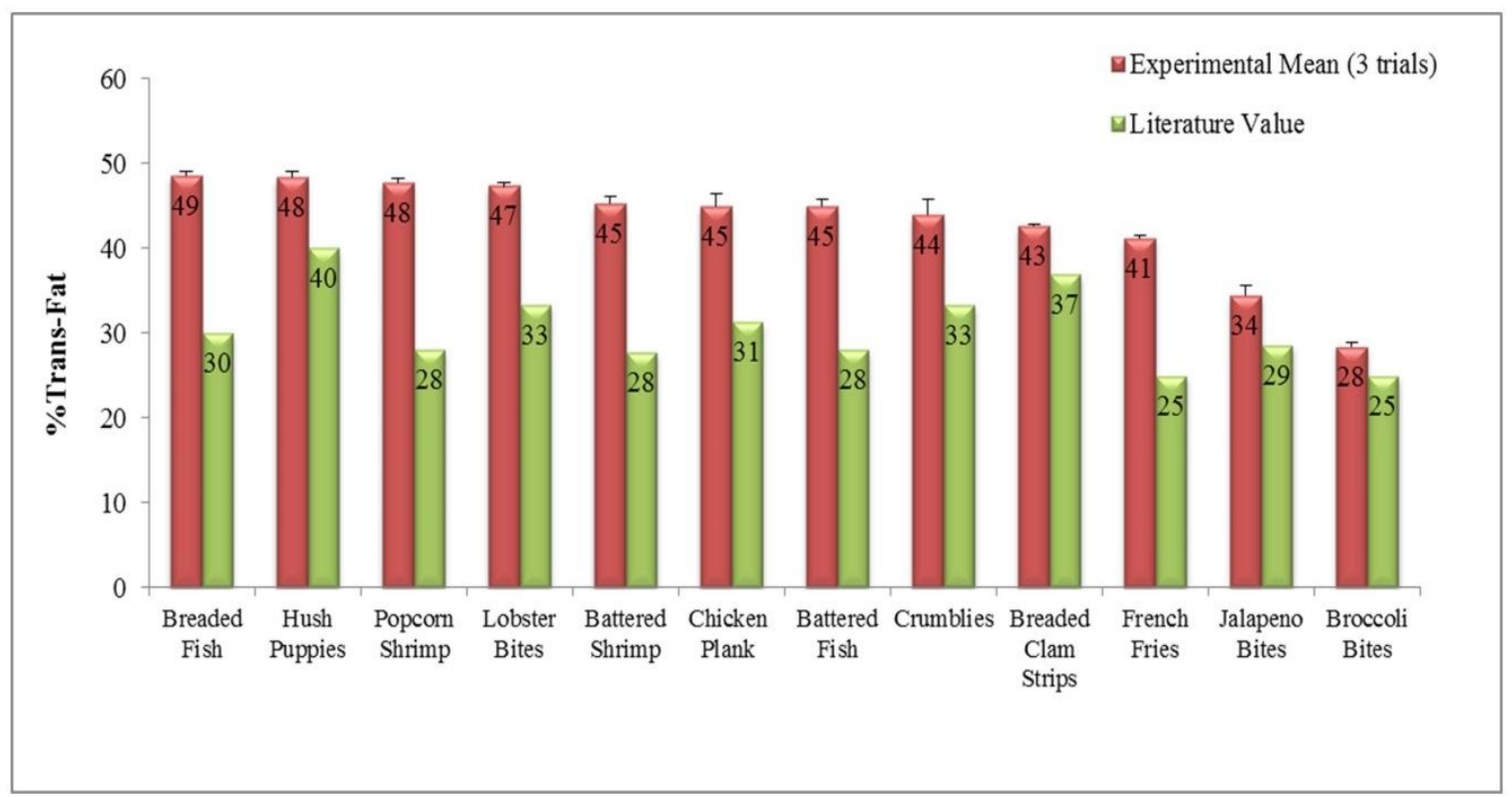

Fig. 2. Experimental and Literature \%Trans-fat values for LJS's Food Items studied

Table 1. A comparison of the experimental and literature values for $\%$ trans-fat and $\%$ fat in oil samples extracted from select LJS's food items. The mean value of three trials and standard deviation from the mean are shown.

\begin{tabular}{lcc:cc}
\hline \multicolumn{1}{c}{$\begin{array}{c}\text { Food Items } \\
\text { Tested }\end{array}$} & $\begin{array}{c}\text { Mean Experimental } \\
\text { \%trans-fat } \\
(n=3)\end{array}$ & $\begin{array}{c}\text { Literature } \\
\text { \%trans-fat } \\
(2010)\end{array}$ & $\begin{array}{c}\text { Mean Experimental } \\
\text { \%total fat } \\
(n=3)\end{array}$ & $\begin{array}{c}\text { Literature } \\
\text { \%total fat } \\
(2010)\end{array}$ \\
\hline Breaded Fish & $49.0 \pm 0.5$ & 30 & $10.6 \pm 0.2$ & 13 \\
Hush Puppies & $48.4 \pm 0.6$ & 40 & $13.3 \pm 0.9$ & 9.6 \\
Popcorn Shrimp & $47.7 \pm 0.5$ & 28 & $9.9 \pm 1.3$ & 19 \\
Lobster Bites & $47.3 \pm 0.4$ & 33 & $11.8 \pm 1.8$ & 9.9 \\
Battered Shrimp & $45.2 \pm 0.9$ & 28 & $24.4 \pm 2.6$ & 21 \\
Chicken Plank & $45.0 \pm 1.5$ & 31 & $15.5 \pm 0.2$ & 15 \\
Battered Fish & $44.9 \pm 0.6$ & 28 & $13.4 \pm 0.9$ & 17 \\
Crumblies & $44.0 \pm 1.9$ & 33 & $45.3 \pm 2.3$ & 22 \\
Breaded Clams & $42.7 \pm 0.2$ & 25 & $17.7 \pm 0.2$ & 12 \\
French Fries & $41.2 \pm 0.2$ & 29 & $11.2 \pm 3.7$ & 17 \\
Jalapeno Bites & $34.4 \pm 1.2$ & 25 & $14.0 \pm 1.3$ & 13 \\
Broccoli Bites & $28.4 \pm 0.4$ & & $8.8 \pm 1.5$ & \\
\hline
\end{tabular}

The \%total fat extracted from each food item was compared with \%total fat reported in LJS's literature (Fig. 3). Statistically, the experimental values for \%fat agreed with the literature values with one exception. Jalapeno bites contained $19 \%$ fat instead of the $10 \%$ reported in the literature. It is important to note that nine out of 12 food items contained over $40 \%$ fat.

\section{Conclusions}

Our study suggests that at the time of this study (2010) trans-fat content in LJS's food items were much higher than what was actually reported in the restaurant's literature. This could be due to differences in method of trans-fat analysis, inaccurate or out-of-date reporting. Since our lab used one of the latest methods in trans-fat analysis, the data reported here has significant implications and further studies are warranted. There are no U.S. federal regulations of trans-fat content in fast foods; 
therefore it is important that trans-fat claims and trans-fat labelling are accurate and up to date so that consumers are able to make healthy and informed food choices when dining in these establishments.

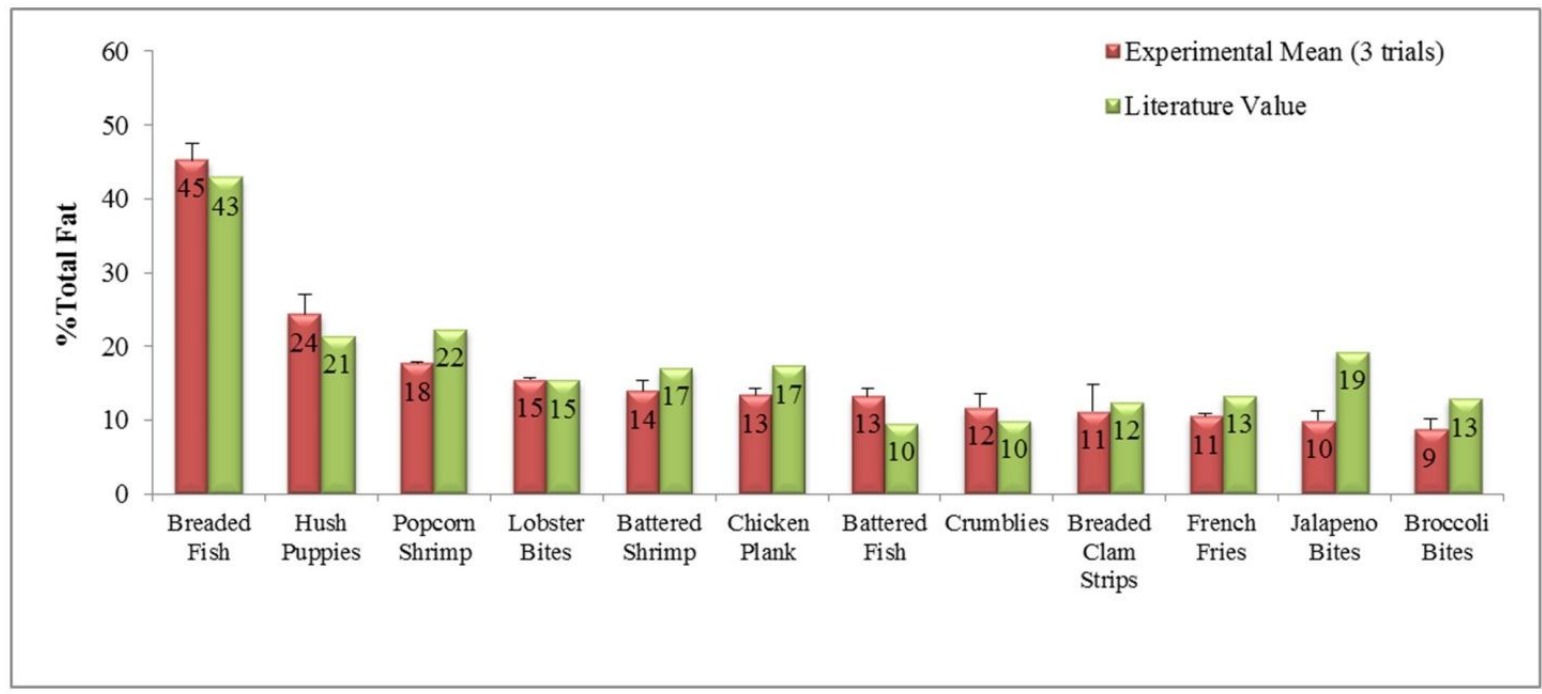

Fig. 3. Experimental and Literature \%Fat values for LJS's food Items studied

\section{Acknowledgements}

This research was funded by LSAMP (Louis Stokes Alliance for Minority Participation) and Purdue University North Central.

\section{Experimental}

\subsection{Materials and Methods.}

A detailed method for fat extraction and trans-fat analysis is described in a previous paper ${ }^{12}$; however a brief description is given here.

\subsection{Fat Extractions.}

On three different days, twelve different food items were purchased from Long John Silver's in Michigan City, a small city in Northwest Indiana. The twelve food items studied were as follows: Breaded Fish, Hush Puppies, Popcorn Shrimp, Lobster Bites, Battered Fish, Batter Shrimp, Chicken Planks, Crumblies, Breaded Clam Strips, French Fries, Jalapeno Bites and Broccoli Bites. On the same day of purchase, the entire order for each food item was massed and homogenized in ligroine (petroleum ether) using a stainless steel blender ${ }^{13,14}$. Access ligroine was decanted, the oil sample was transferred to a large evaporating dish and remaining solvent was evaporated over a low heat ${ }^{12}$ using a hot plate. The oil extracts were stored at $-20^{\circ} \mathrm{C}$ until IR analysis and VFA-IR trans-fat analyses were done within 24 hours of fat extraction. See our previous study for detailed procedure for fat extraction $^{12}$. Our previous studied show that evaporation over low heat and short-term storage at $20^{\circ} \mathrm{C}$ did not affect the \%trans-fat results.

\subsection{Trans-fat Analysis.}

Variable Filter Array (VFA) IR spectroscopy ${ }^{11,15}$ was used to determine the total isolated trans fatty acid in neat oil extracts. The InfraSpec VFA-IR spectrometer (Figure 4) is a newly patented mid-IR instrument that utilizes a detector array with linear variable filter. VFA-IR spectroscopy is based on ATR-FTIR trans-fat analysis and was used to determine the total isolated trans fatty acid in neat oil sample extracts ${ }^{11,12,15}$. This method of VFA-IR trans-fat analysis can only be applied to oils 
and fats with trans-fat levels equal to or greater than about $1.0 \%$. The InfraSpec VFA-IR Spectrometer was equipped with custom software that allowed for multiple calibrations and data storage. After fat extraction from samples, approximately $100 \mathrm{ul}$ of fat extract was needed for VFAIR analysis.

The VFA-IR instrument has a resolution of $25 \mathrm{~cm}^{-1}$, hence the trans-fat absorption bands of standards and samples occurred at $956 \mathrm{~cm}^{-1}$ instead of $966 \mathrm{~cm}^{-1}$ which was within the resolution of the instrument. The area under the $956 \mathrm{~cm}^{-1}$ trans absorbance band was integrated between the limits of 945 and $990 \mathrm{~cm}^{-1}$ in order to obtain the peak area of all samples and standards. The cis fatty acid standard triolein was used as the background spectrum for all VFA-IR analyses ${ }^{11,15,16}$.

The VFA-IR instrument was calibrated using standards prepared from triolein (cis-fat standard) and trielaidin (trans-fat standard). Trielaidin and triolein were purchased from Nu-Check-Prep, Elysian, MN. Triolein is an oleic acid triglyceride containing only cis double bonds, and trielaidin is an elaidic acid triglyceride containing only trans double bonds. Eight trans-fat calibration standards were prepared by mixing trielaiden and triolein to give percentages of trans-fat between one and $50 \%$ by mass. Figure 5 shows the VFA-IR absorbance spectra and calibration curve of the eight trans-fat standards. A plot of percent trans-fat versus peak area $\left(945-990 \mathrm{~cm}^{-1}\right)$ of the standards yielded the linear equation, $\mathrm{y}=4.77 \times 10^{-5} \mathrm{x}+1.23 \times 10^{-4}, \mathrm{R}^{2}=0.9904$ (Figure $5 \mathrm{~B}$ ). See our previous study for detailed procedure for trans-fat analysis ${ }^{12}$.

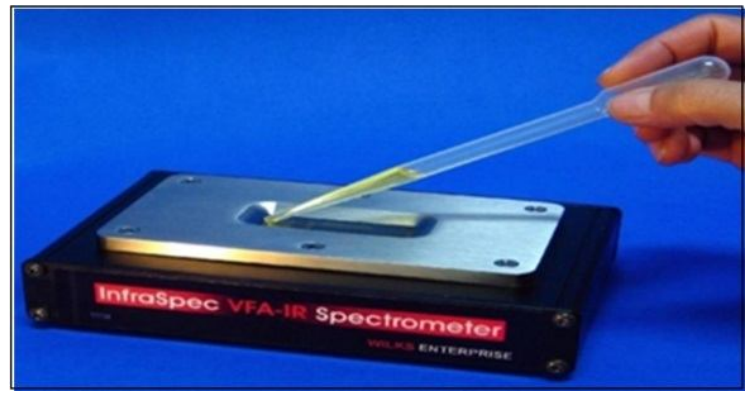

Fig. 4. Wilk's InfraSpec VFA-IR Spectrometer ${ }^{17}$

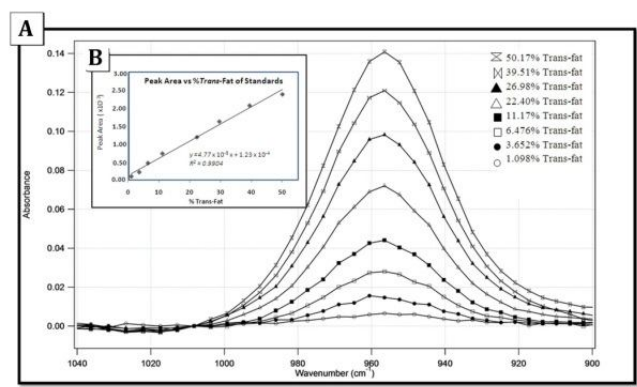

Fig. 5. Figure 5A is a VFA-IR absorption spectra of the trans-fat calibration standards and Figure 5B shows a graph of the percent trans-fat verses peak area $\left(945-990 \mathrm{~cm}^{-1}\right)$ which yields a linear equation, $\mathrm{y}$ $=4.77 \times 10^{-5} \mathrm{x}+1.23 \times 10^{-4}\left(\mathrm{R}^{2}=0.9904\right)$

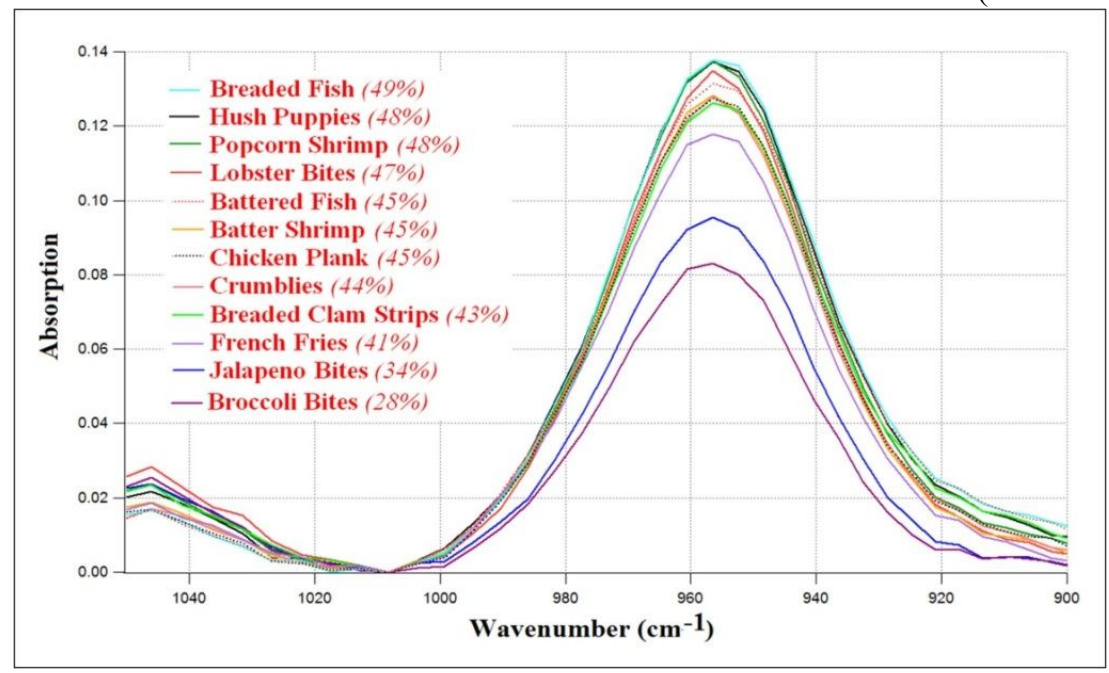

Fig. 6. Figure 6 is a VFA-IR absorption spectrum of sample oil extractions 


\section{References}

1. Graf P. A., Lemke S., Dirienzo M. (2008) Reducing the Trans-Fatty Acid Content in Foods. Nutr. Toda., 43(2), 46-51

2. Hu F. B., Stampfer M.J., Manson J.E., et al. (1997) Dietary Fat Intake and the Risk of Coronary Heart Disease in Women. N. Engl. J. Med., 333(21), 1491-1499

3. Willett W.C. (2006) Trans fatty acids and cardiovascular disease - epidemiological data. Atherosclerosis Supp., 7(2), 5-8

4. Leth T., Jensen H. G., Mikkelsen A., et al. (2006) The effect of the regulation on trans fatty acid content in Danish food. Atherosclerosis Supp., 7(2), 53-56

5. Revealing Trans Fats. (2003) FDA Consum., Pub No FDA05-1329C

6. Willet W.C., Mozaffarian D. (2007) Trans fats in cardiac diabetes risk: An overview. Curr. Cardiovasc. Risk Rep.,1(1):16-23

7. Mozaffarian D., Willett W. (2007) Trans fatty acids and cardiovascular risk: A unique cardiometabolic imprint? Curr. Atheroscler. Rep., 9(6):486-493.

8. Trans fat.(2009) J. Am. Heart Assoc., http://www.americanheart.org/presenter.jhtml?identifier=3045792

9. New York City Department of Health and Mental Hygiene (2006) New York City Health Code Section 81.08, http://www.nyc.gov/html/doh/downloads/pdf/public/notice-adoption-hc-art8108.pdf

10. Borra S., Kris-Etherton P. M., Dausch J. G. (2007) An Update of Trans-Fat Reduction in the American Diet. J. Am. Diet Assoc., 107(12), 2048-2050

11. A.O.C.S., Rapid Determination of Isolated trans Geometric Isomers in Fats and Oils by Attenuated Total Reflection Infared Spectroscopy, 1999, Official Method Cd 14d-99

12. Jenkins S., Campbell P., and Burch C. (2012) Are fast food "trans-fat" claims true? An Infraspec VFA-IR spectrometer analysis of trans-fat content in fast food French fried potatoes. Proc. Indiana Acad. Sci., 121(1), 8-16.

13. Bligh, E.G. and Dyer, W. J. (1959) A rapid method of total lipid extraction and purification. Can. J. Biochem. Physiol., 37, 911-917.

14. Sheppard A. J., Hubbard W. D., Prosser A. R, (1974) Evaluation of eight extraction methods and their effects upon total fat and gas liquid chromatographic fatty acid composition analyses of food products. J. Am. Oil Chem. Soc., 51(9), 416-418

15. Mossoba M., Milosevic V., Milosevic M., et al., Determination of total trans fats and oils by infrared spectroscopy for regulatory compliance. Anal. Bioanal. Chem., 389(1), 87-92

16. Mossoba M. M., Yurawecz M. P., McDonald R. E. (1996) Rapid determination of the total trans content of neat hydrogenated oils by attenuated total reflection spectroscopy. J. Am. Oil Chem. Soc., 73(8), 1003-1009

17. Wilks - A Spectro Inc. Company (2014) Trans Fatty Acid Measurement, http://www.wilksir.com/pdf/Trans\%20Fat_2-14.pdf A.O.C.S. 